\title{
Co-Circulation of All Dengue Serotypes among Patients Attending a Tertiary Care Hospital in Kolkata
}

\author{
Dey $\mathbf{M}^{1}$, Sengupta $\mathbf{M}^{1}$, Chatterjee $\mathrm{RP}^{2}$, Sarkar $\mathrm{S}^{1}$, Chatterjee $\mathrm{S}^{3}$ and \\ Barik G1* \\ ${ }^{1}$ Department of Microbiology, Medical College, Kolkata, India \\ 2ICMR Virus Unit, NICED, Kolkata, India \\ ${ }^{3}$ Scientist-D, ICMR Virus Unit, NICED, Kolkata, India
}

\section{Research Article}

Volume 2 Issue 9

Received Date: August 02, 2018

Published Date: August 14, 2018

${ }^{*}$ Corresponding author: Dr. Gautam Barik, Associate Professor, Department of Microbiology, Medical College, Kolkata, 88, College Street, Kolkata-73, India, Email: gautambarik@gmail.com

\begin{abstract}
The Dengue virus (DENV), a mosquito-borne member of the family Flaviviridae, has four distinct serological types DENV 1, DENV 2, DENV 3, and DENV 4. Between August and December 2016, a total of 2938 samples were tested. 658(22.4\%) were IgM-positive out of 1654 samples while 298(10.1\%) were NS1-positive out of 1284 samples tested. The age group most susceptible to dengue infection was 21-30 years. During monsoon and post monsoon seasons, the number of IgM and NS1 positive cases increased. The outbreak was more prevalent in urban (83.9\%) than rural (16.1\%) areas. RT-PCR was done for 131 random NS1 positive samples, of which 37(28.2\%) were found positive. Circulating serotype was predominantly DEN2 (14), followed by DEN1 (10), DEN3 (8) and DEN4 (4), and one case of co-infection with both DEN1 and DEN4.
\end{abstract}

Keywords: Dengue; Serotypes; Prevalence; PCR; Kolkata; IgM; NS1

\section{Introduction}

The $21^{\text {st }}$ century put forth a plethora of new opportunities for the globalization of ideas, individuals, and infections, impelled by increasing interconnectivity and global environmental change. India is one of the seven countries in the South-East Asia region, regularly reporting incidence of Dengue Fever/Dengue Haemorrhagic Fever outbreaks because of its high incidence which constantly threatens the health care system. The first epidemic of clinical dengue-like illness was recorded in Madras (now Chennai) in 1780 and the first virologically proved epidemic of Dengue Fever in India occurred in Calcutta and Eastern Coast of India in 1963-1964 [1-3]. Since then more and more new states have been reporting the disease often in epidemic proportions, causing huge morbidity and mortality [4-7]. The aetiology of dengue viruses was first established in Kolkata in 1963 (July to March) with DEN-2 as the serotype incriminated then [8-13]. 


\section{Virology \& Immunology Journal}

Dengue viruses belong to the family Flaviviridae, genus Flavivirus. It has four serotypes: DENV-1, DENV-2, DENV-3 and DENV-4. The transmission between vertebrate hosts including humans is dependent on haematophagous arthropod vectors, most importantly Aedes aegypti in urban tropical settings. Dengue is the most common arthropod-borne viral infection in the world $[14,15]$. Each of the four distinct serotypes of dengue virus (DENV) can cause disease symptoms ranging from self-limited febrile illness called dengue fever (DF) to dengue hemorrhagic fever (DHF) and dengue shock syndrome (DSS) $[15,16]$.

The present study of the outbreak in 2016 was undertaken to find out and categorize the prevalence of DENV serotype by screening the patients for Dengue IgM antibody and/or NS1 antigen by ELISA followed by RTPCR of NS1 positive serum.

\section{Materials and Methods}

Ethical Clearance: The proposal of the study and other relevant documents were submitted to Institutional Ethics Committee of Medical College, Kolkata for review and approval. The study was conducted after getting approval in writing on $27^{\text {th }}$ August, 2016.

Study Area: Department of Microbiology, Medical College, Kolkata and ICMR Virus Unit, ID \& BG Hospital, Beliaghata, Kolkata.

Study Population: Patients from Kolkata and adjoining districts of West Bengal, of different age groups and both genders who came to Medical College \& Hospital, Kolkata with a history of fever and were clinically suspected to be suffering from dengue were included in the study. Sample size was not determined a priori since the study enrolled all patients admitted during the study period who had febrile illness, clinically suspected to be dengue and were referred to Department of Microbiology for laboratory confirmation.

\section{Study Period}

1. Samples were collected during August to December 2016 after obtaining the IEC clearance.

2. Patients with fever for less than 5 days were tested for Dengue NS1 antigen and that of more than/equal to 5 days were tested for Dengue IgM antibody.

3. NS1 positive samples were transferred to ICMR Virus Unit in November/December 2016.

4. Molecular studies for dengue serotype were done from December 2016 to February 2017.
5. Result analysis was done from March 2017 to April 2017.

\section{Subject Selection Criteria}

Inclusion Criteria: Blood samples from all patients with fever clinically diagnosed as dengue coming to Department of Microbiology for NS1 and IgM screening were included in this study.

Exclusion Criteria: Patients with other diseases coming to Department of Microbiology for other investigations and also patients unwilling to give consent or blood were excluded from this study.

\section{Examination of Blood}

Blood was collected, serum was separated and stored at $-20^{\circ} \mathrm{C}$ until further testing.

\section{Enzyme Linked Immuno Sorbent Assay (ELISA)}

The serum samples of patients were tested for Dengue IgM antibody with history of fever for equal to or more than 5 days and Dengue NS1 antigen with history of fever for less than 5 days, using commercial kits as per availability. The commercial kits included NIV Dengue IgM Capture ELISA manufactured by National Institute of Virology (NIV), \& PanBio Dengue Early ELISA manufactured by Panbio Diagnostics for NS1 detection respectively.

\section{RNA Extraction}

To study the molecular typing of DENV, attempts were made to isolate the RNA from random NS1 positive samples. Viral RNA was isolated by using Qiagen viral RNA isolation kit (Qiagen, GmbH, Hilden, Germany) according to the manufacturer's protocol. The eluted RNA was stored at $-20^{\circ} \mathrm{C}$ until the further processing.

\section{Reverse Transcription Polymerase Chain Reaction (RT-PCR)}

In this study, published primers by Lanciotti et al. were used. In a single tube, viral RNA was converted to a DNA copy (cDNA) prior to enzymatic DNA amplification by the use of reverse transcriptase (RT) and the DENV downstream consensus primer D25_TTGCACCAACAGTCAATGTCTTCAGGTTC_3 homologous to the genomic RNA of the four serotypes. c-DNA was transcribed using nuclease free water, 5X RT Buffer, RT Enzyme, RNAs in, Random Hexamer, dNTP mixed with the RNA product followed by centrifuge for 15 seconds. Reverse Transcription was carried out in thermocycler at 


\section{Virology \& Immunology Journal}

$42^{\circ} \mathrm{C}$ for 1 hour. The c-DNA thus obtained was stored at $20^{\circ} \mathrm{C}$ until further process.

Subsequent Taq polymerase amplification was performed on the resulting cDNA with the upstream dengue virus consensus primer D15_TCAATATGCTGAAACGCGCGAGAAACCG-3_. Target RNA was amplified using nuclease free water, Emerald Master Mix, Dengue Primer 1 (D1) and Dengue Primer 2 (D2), then mixed by vortex and brief centrifuge. The reactions were allowed to proceed with $94^{\circ} \mathrm{C}$ for 2 minutes for initial denaturation followed by 35 cycles of denaturation $\left(94^{\circ} \mathrm{C}\right.$ for $\left.30 \mathrm{sec}\right)$, primer annealing $\left(50^{\circ} \mathrm{C}\right.$ for $\left.30 \mathrm{sec}\right)$, and primer extension $\left(72^{\circ} \mathrm{C}\right.$ for $\left.1 \mathrm{~min}\right)$ along with final extension $\left(72^{\circ} \mathrm{C}\right.$ for $\left.10 \mathrm{~min}\right)$.

DENV serotyping was conducted by second-round amplification (nested PCR) initiated with diluted material (1:100 in nuclease free water) from the initial amplification reaction. The total reaction mixture was prepared using diluted first PCR products, Emerald Master Mix, Dengue Primer D1 and Dengue virus typespecific primers: TS1 5_-CGTCTCAGTGATCCGGGGG- 3_ (482bp), TS2 5_-CGCCACAAGGGCCATGAACAG-3_(119bp), TS3 5_ -TAACATCATCATGAGACAGAGC-3_ (290bp), and TS4 5_-CTCTGTTGTCTTAAACAAGAGA-3_ (392bp).

The samples were subjected to initial denaturation $\left(94^{\circ} \mathrm{C}\right.$ for $2 \mathrm{~min})$ followed by 35 cycles of denaturation $\left(94^{\circ} \mathrm{C}\right.$ for $30 \mathrm{sec})$, primer annealing $\left(50^{\circ} \mathrm{C}\right.$ for $\left.30 \mathrm{sec}\right)$, and primer extension $\left(72^{\circ} \mathrm{C}\right.$ for $\left.1 \mathrm{~min}\right)$ along with final extension $\left(72^{\circ} \mathrm{C}\right.$ for $\left.10 \mathrm{~min}\right)$. The PCR products were analyzed by running a $1.5 \%$ agarose gel stained with ethidium Bromide.

\section{Data Analysis}

For statistical analysis data were enrolled into a Microsoft Excel spreadsheet and then analyzed by Epi Info 7, and GraphPad Prism version 5. Data were summarized as mean and standard deviation for numerical variables and counted and percentages for categorical variables were enumerated. The median and the interquartile range have been stated for variables that are not normally distributed. Student's independent sample's t-test was applied to compare normally distributed numerical variables between groups; unpaired proportions were compared by Chi-square test or Fischer's exact test, as appropriate. The p-value was calculated wherever required and value $\leq 0.05$ was considered to be statistically significant.

\section{Results and Analysis}

A total of 2938 samples were included in this study, from patients who were referred from IPD \& OPDs of Medical College, Kolkata, during the period August 2016 to December 2016. Serum samples of patients with less than 5 days fever amounting to 1284, were tested for the presence of dengue NS1 antigen by ELISA, out of which 298 (23.2\%) were found to be positive. Serum samples of patients with more than or equal to 5 days fever amounting to 1654 , were tested for the presence of dengue IgM antibody by ELISA, out of which 658 (39.8\%) were found to be positive.

Dengue outbreak was more prevalent in urban areas than rural areas in 2016 (Figure 1). There were 803 positive cases out of 1026 samples from urban region and 153 positive cases out of 956 samples from rural areas.

Among 1730 male patients, 577 were positive while among 1208 female patients 379 were positive for Dengue NS1 or IgM antibody (Figure 2).

There was a surge in the number of IgM reactive cases during the month of September, 185 out of 1654 samples. But the number of NS1 reactive cases were more during the month of October, 83 out of 1284 (Figure 3).

The age group of 21 to 30 years, irrespective of sex, was found to be more susceptible to dengue infection as can be noted from the higher number of positive cases in this age group for both IgM, $173(18.09 \%)$ and NS1, 92 (9.62\%), out of 956 positive samples (Figure 4).

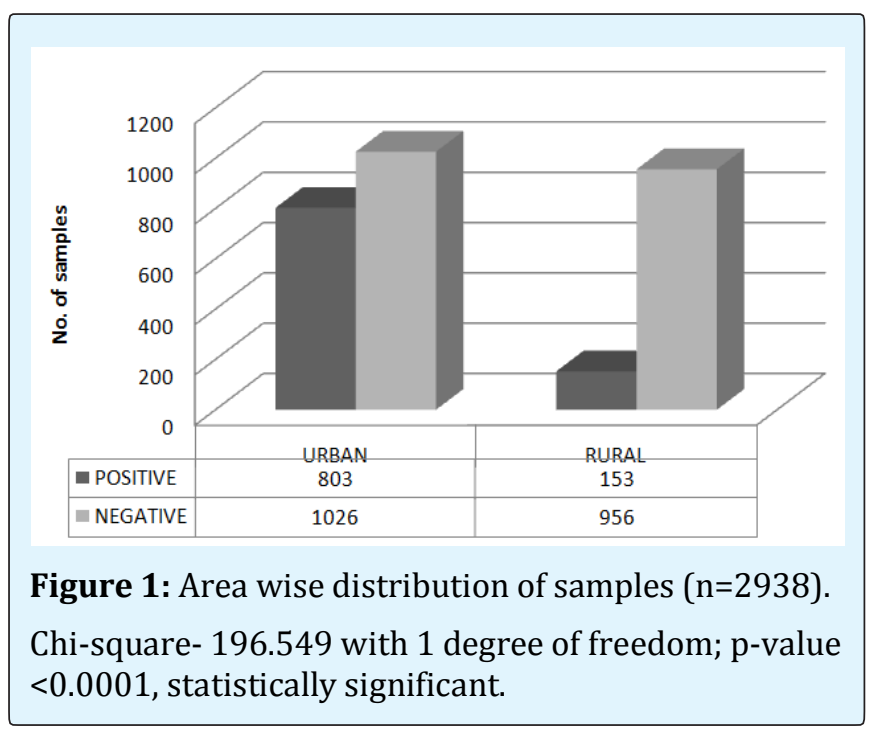




\section{Virology \& Immunology Journal}

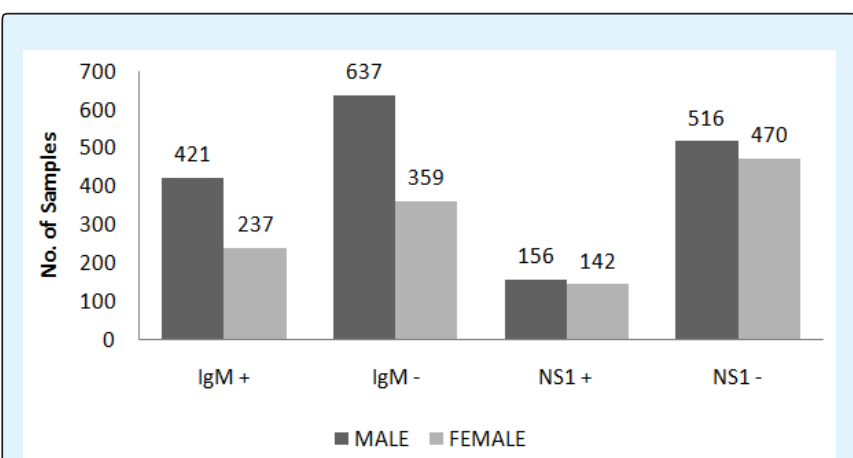

Figure 2: Sex wise distribution of samples ( $\mathrm{n}=2938)$.

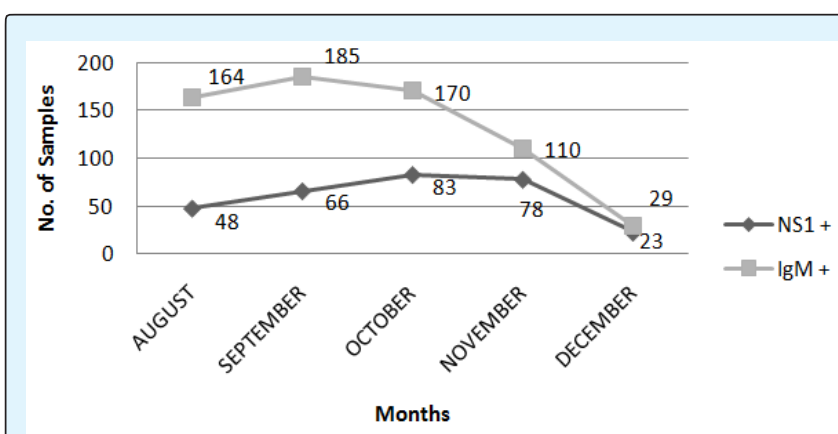

Figure 3: Month wise distribution of ELISA positive serum samples $(\mathrm{n}=956)$.

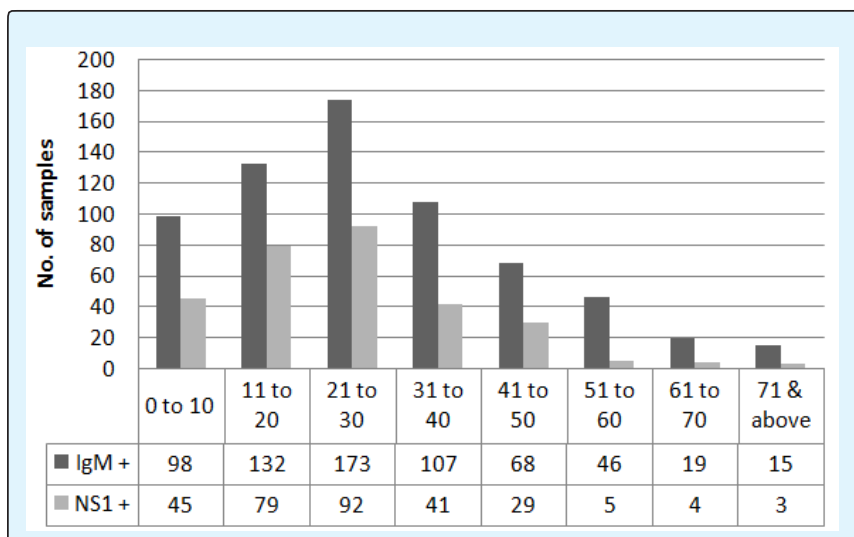

Figure 4: Age wise distribution of positive samples $(n=956)$.

298 samples were NS1 positive, out of which 131 samples were tested for the presence of Dengue virus by RT-PCR. 37 samples were PCR positive, DEN2 was the most prevalent serotype in the year 2016 amounting to 14 (37.9\%), followed by DEN1, 10 (27\%), DEN3, 8 (21.6\%), DEN4, 4 (10.8\%), and 1 case of dual infection with both Den1 and Den4 (2.7\%) (Figure 5).

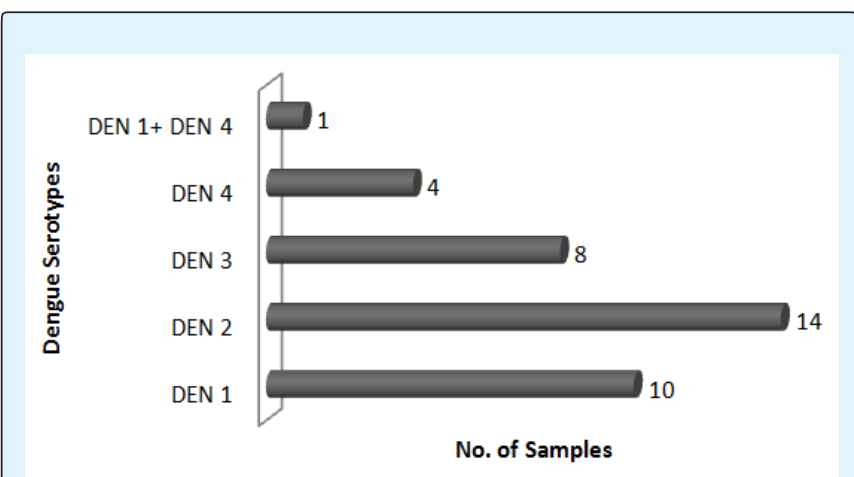

Figure 5: Distribution of samples according to Dengue Serotype among the PCR positive serum samples $(n=37)$.

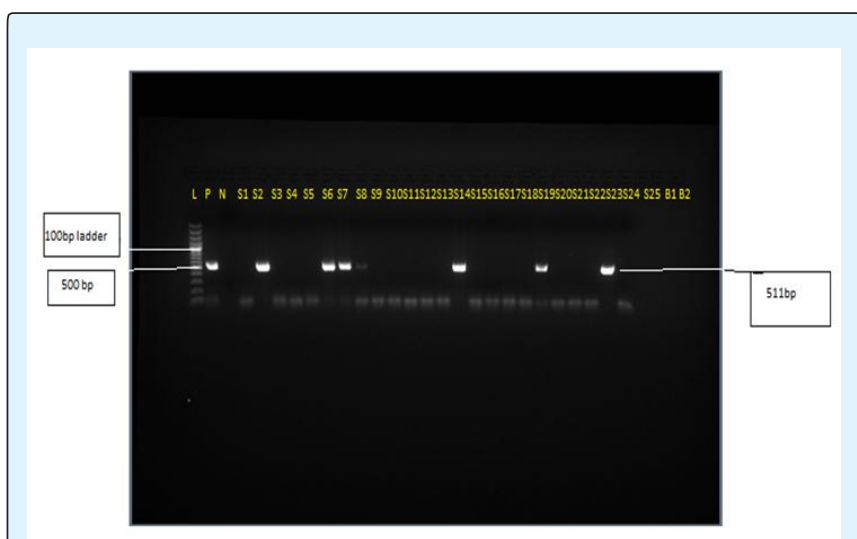

Figure 6: Result of Dengue-specific RT-PCR, showing bands in 1.5\% Agarose gel electrophoresis stained with Ethidium bromide. Lane L: 100bp DNA ladder; Lane 2: positive control: Lane 3: negative control; Lanes S2, S6, S7, S14, S19 and S23 are PCR positive samples of patients.

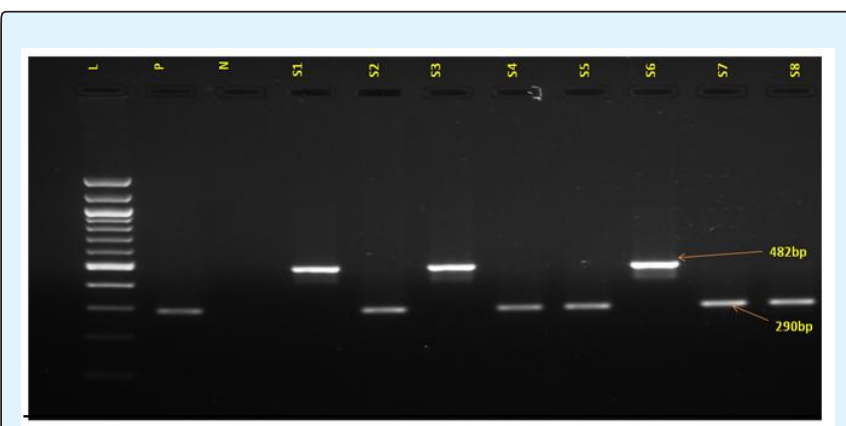

Figure 7: Results of Dengue-specific RT-PCR followed by second-round nested PCR of RNA samples, showing band in 1.5\% Agarose gel electrophoresis stained with Ethidium bromide. Lane L: 100bp DNA ladder, Lanes S1, S3, S6 with DEN1 (482bp) and Lanes S2, S4, S5, S7 and S8 with DEN3 (290bp). 


\section{Virology \& Immunology Journal}

\begin{tabular}{|c|c|c|c|c|c|c|c|c|c|}
\hline \multicolumn{2}{|c|}{ Observations } & Mean & $\begin{array}{c}\text { Standard } \\
\text { Deviation }\end{array}$ & Minimum & $\mathbf{2 5 \%}$ & Median & $\mathbf{7 5 \%}$ & Maximum & Mode \\
\hline PCR + & 94 & 24.2553 & 14.6199 & 1 & 16 & 21 & 32 & 65 & 20 \\
\hline PCR - & 36 & 20.2778 & 13.7334 & 1 & 10.5 & 20 & 25 & 62 & 20 \\
\hline
\end{tabular}

Table 1: Distribution of mean age among PCR positive and PCR negative samples (n=131). $\mathrm{p}$-value $=0.16069$, Bartlett's chi square $=0.18000$, statistically not significant.

\begin{tabular}{|c|c|c|c|c|c|c|c|c|c|}
\hline \multicolumn{2}{|c|}{ Observations } & Mean & $\begin{array}{c}\text { Standard } \\
\text { Deviation }\end{array}$ & Minimum & $\mathbf{2 5 \%}$ & Median & $\mathbf{7 5 \%}$ & Maximum & Mode \\
\hline PCR + & 94 & 3.2766 & 1.3231 & 1 & 2 & 3 & 5 & 5 & 5 \\
\hline PCR - & 36 & 2.5278 & 0.9098 & 1 & 2 & 2.5 & 3 & 5 & 2 \\
\hline
\end{tabular}

Table 2: Distribution of mean duration of fever among PCR positive and negative samples ( $\mathrm{n}=131)$. p-value $=0.00223$, Bartlett's chi square $=6.22555$, statistically significant.

\section{Discussion}

Dengue is a multidimensional global public health concern. The outbreak during the year 2016 was found to be more in urban areas that corroborates with studies conducted by A K Hati, S. Chatterjee et al, along with another publication by A. Sarkar, et al. [17-19]. A small water container such as plastic tea cup, water bottles, chips packets, tyres, coconut shells, earthen pots, etc., newly constructed buildings, collected water especially in the unhygienic slum areas, and was present which favored mosquito breeding.

Dengue was more prevalent among male as compared to female which was in accordance with the studies by Sarmila, et al. and Rashmi, et al. whereas female preponderance was seen in studies by Ankita, et al. and Sri hari, et al. [20,23]. The difference in distribution among both sexes is probably due to their greater number and greater exposure to the vector for males as compared to females.

The majority of the cases were outlined in the month of September, 2016, which was in accordance with the reported patterns of dengue transmission by P. Reiter that showed maximum number of cases during the monsoon and post-monsoon seasons [24]. This was evident for both IgM and NS1, in which there were 185 positive cases for IgM and 83 positive cases for NS1. During monsoon and post monsoon seasons, the rain water getting collected due to lack of awareness among people led to the breeding grounds for mosquitoes.

The age group more susceptible to Dengue infection was 21 to 30 years as was evidenced in studies of Gupta et al. and Chakravarti and Kumaria [25,26]. This could be probably due to the fact that this age group comprises of the young adults getting more affected which reflects the presence of non-immune adult population falling prey to the circulating serotype of dengue virus. Moreover, this age group is extensively involved in outdoor activities and move to different places away from home for purposes like job etc. which could contribute to the spread of this highly infectious dengue disease. Sarkar et al., however, reported maximum cases in the age group 0-10 years with female preponderance [27].

Den3 outbreaks were also previously reported in Kolkata in 1983 and in 2005 [28,29]. Sarkar, et al., however, reports the co-circulation of all the four dengue serotypes with predominance of Den2 in 2010 [27]. In 2012, Den1 was reported to be the predominant serotype along with Den3 and Den4 [30].

\section{Conclusion}

Dengue continues to involve newer areas, newer populations and is increasing in magnitude, epidemic after epidemic. During the Dengue outbreak of 2016, the urban population was more affected as compared to the rural population as indicated by the study. Thus it can be concluded that dengue is a substantial cause of febrile illness in Kolkata. The most susceptible age group was 21 to 30 years and the sex-wise distribution showed more male patients to be dengue positive. Community awareness, confirmatory diagnosis and management and vector control measures need to be strengthened, during and post-monsoon period, in order to curb the increasing number of dengue cases.

The study showed all four types of DENV are circulating in Kolkata and Den2 is the dominant serotype. 


\section{Virology \& Immunology Journal}

This information may interpret dengue burden estimates and populate transmission models to assess the potential impact of prevention and control measures, including vaccination programmes.

\section{References}

1. Sarkar JK, Chatterjee SN, Chakravarty SK (1964) Haemorrhagic fever in Calcutta: some epidemiological observations. Indian J Med Res 52: 651-659.

2. Chatterjee SN, Chakravarti SK, Mitra AC, Sarkar JK (1965)Virological investigation of cases with neurological complications during the outbreak of haemorrhagic fever in Calcutta. J Indian Med Assoc 45(6): 314-316.

3. Carey DE, Myers RM, Reuben R, Rodrigues FM (1966) Studies on dengue in Vellore, South India. Am J Trop Med Hyg 15(4): 580-587.

4. Balaya S, Paul SD, D'Lima LV, Pavri KM (1969) Investigations on an outbreak of dengue in Delhi in 1967. Indian Journal of Medical Research 57(4): 767774.

5. Rodrigues FM, Patankar MR, Banerjee K, Bhatt PN, Goverdhan MK, et al. (1972) Etiology of the 1965 epidemic of febrile illness in Nagpur city, Maharashtra State, India. Bulletin World Health Organization 46(2): 173-179.

6. Padbidri VS, Dandawate CN, Goverdhan MK, Bhat UK, Rodrigues FM, et al. (1973) An investigation of the aetiology of the 1971 outbreak of febrile illness in Jaipur city, India. Indian Journal of Medical Research 61(12): 1737-1743.

7. Karamchandani PV (1937) Study of 100 cases of dengue fever in Madras Penitentiary. Indian Med Gazette 72(9): 532-534.

8. Sarkar JK, Pavri KM, Chatterjee SN, Chakravarty SK, Anderson CR (1964) Indian J Med Res 52: 684.

9. Pavri KM, Banerjee G, Anderson CR, Aikat BK (1964) Indian J Med Res 52: 692.

10. Aikat BK, Konar NR, Banerjee G (1964) Indian J Med Res 52: 660.

11. Ramakrishnan SP, Gelfand GM, Bose PN, Sehgal PN, Mukherjee RN (1964) Indian J Med RPS 52: 633.
12. Sarkar JK, Chatterjee SN, Chakravarty SK (1964) Indian J Med Res 52: 651.

13. Ramachandra RT, Anderson CR (1964) Indian J Med Res 52: 727.

14. Gubler DJ (2006) Dengue/dengue haemorrhagic fever: history and current status. Novartis Found Symp 277: 3-16.

15. World Health Organization. WHO report on global surveillance of epidemic-prone infectious diseasesdengue and dengue haemorrhagic fever.

16. Halstead SB (1970) Observations related to pathogenesis of dengue hemorrhagic fever. VI. Hypotheses and discussion. Yale J Biol Med 42(5): 350-362.

17. Hati AK (2009) Dengue serosurveillance in Kolkata, facing an epidemic in West Bengal, India. Journal of Vector Borne Diseases 46(3): 197-204.

18. Taraphdar D, Sarkar A, Bhattacharya MK, Chatterjee S (2010) Sero diagnosis of dengue activity in an unknown febrile outbreak at the Siliguri Town, District Darjeeling, West Bengal. Asian Pacific Journal of Tropical Medicine 3(5): 364-366.

19. Sarkar A, Taraphdar D, Chatterjee S (2010) Investigations of recurrent outbreaks of unknown fever, establish rural dengue activity in West Midnapore, a costal district in West Bengal, India. Archives of Clinical Microbiology 1(4).

20. Raut S, Patil A (2012) Dengue In and Around NagpurCentral India. Journal of Evolution of Medical and Dental Sciences 1(5): 853.

21. Rashmi KS, Jagadeesh, Ravikumar KL, Pratibha Malini J, Giridhar UP, et al. (2013) Serological markers prevalence and trend of probable dengue infection at a tertiary care hospital in Bangalore. Journal of Evolution of Medical and Dental Sciences 2(36): 6968-6976.

22. Nisarta A, Ahir H (2016) Study of Seroprevalence of Dengue Virus Infection in a Tertiary Care Hospital in Patan, Gujarat, India. Int J Curr Microbiol App Sci 5(10): 819-824.

23. Shrihari N, Kumudini TS, Mariraj J, Krishna S (2012) The Prevalence of Arboviral diseases mainly Dengue, Chikungunya and Japanese B Encephalitis in and 


\section{Virology \& Immunology Journal}

around Bellary district, Karnataka. Journal of Pharmaceutical and Biomedical Sciences (JPBMS) 15(15).

24. Reiter P (2001) Climate change and mosquito-borne disease. Environmental Health Perspectives 109(1): 141-161.

25. Gupta E, Dar L, Kapoor G, Broor S (2006) The changing epidemiology of dengue in Delhi, India. Virology Journal 3: 92.

26. Chakravarti A, Kumaria R (2005) Eco-epidemiological analysis of dengue infection during an outbreak of dengue fever, India. Virology Journal 2: 32.

27. Sarkar A, Taraphdar D, Chatterjee S (2012) Molecular typing of dengue virus circulating in Kolkata, India in 2010. Journal of Tropical Medicine 2012: 5.
28. Mukherjee KK, Chakravarti SK, Dey PN, Dey S, Chakraborty MS (1987) Outbreak of febrile illness due to dengue virus type 3 in Calcutta during 1983. Transactions of the Royal Society of Tropical Medicine and Hygiene 81(6): 1008-1010.

29. Hati AK (2006) Studies on dengue and dengue haemorrhagic fever (DHF) in West Bengal State, India. Journal of Communicable Diseases 38(2): 124129.

30. Bandyopadhyay B, Bhattacharya I, Adhikary S, Konar J, Dawar N, et al (2013) A Comprehensive Study on the 2012 Dengue Fever Outbreak in Kolkata, India. ISRN Virology 2013: 5.

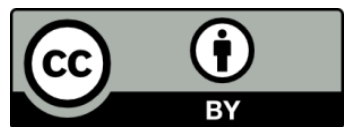

